\title{
Língua e diversidade: imagens sobre africanos e escravidão
}

\section{Language and diversity: images on African slavery}

\author{
Ivana Stolze Lima \\ ivana@rb.gov.br \\ Doutora em História - Bolsista produtividade CNPq \\ Fundação Casa de Rui Barbosa \\ Rua São Clemente, 134, Botafogo \\ 22260-000 - Rio de Janeiro - RJ \\ Brasil
}

\begin{abstract}
Resumo
Neste artigo é identificada e discutida a presença difusa de um tópos que relaciona a diversidade linguística entre os africanos com a incomunicabilidade. Buscando encaminhar esse questionamento, relatos de diferentes agentes ligados ao tráfico atlântico são analisados, sendo os principais os de Antonio Cadornega (História geral das guerras angolanas, 1680), William Smith (New Voyage to Guinea, 1745), Theodore Canot (Captain Canot, or Twenty Years of an African Slaver, 1854) e Bernardo Cannecattim (Dicionário da língua bunda ou angolense, explicada na portuguesa e latina, 1804), além de documentação produzida por autoridades coloniais. A partir disso, e em diálogo crítico com a historiografia do tráfico e da escravidão no mundo atlântico, no artigo são desenvolvidas questões relativas a possíveis políticas linguísticas dirigidas à escravidão, a representações sobre diversidade linguística, ao papel de intérpretes e mediadores do tráfico, bem como, de forma mais ampla, à articulação entre a escravização de africanos e as questões de linguagem e comunicação.
\end{abstract}

\section{Palavras-chave}

Linguagem; Tráfico de escravos; Historiografia sobre escravidão.

\begin{abstract}
This paper identifies and discusses a topos that relates linguistic diversity among Africans with inability to communicate. Reports of different agents directly or indirectly linked to the slave trade on the Atlantic are analyzed, the main ones being Antonio Cadornega (História Geral das Guerras Angolanas, 1680), William Smith (New Voyage to Guinea, 1745), Theodore Canot (Captain Canot, or Twenty Years of an African Slaver, 1854), and Bernardo Cannecattim (Dicionário da Língua Bunda ou Angolense, explicada na portuguesa e latina, 1804), besides historical documentation from colonial authorities. In critical dialogue with the historiography on slave trade and slavery on the Atlantic, this paper raises questions regarding possible language policies aimed at slavery, representations on linguistic diversity, the role of interpreters and mediators, and, more broadly, the nexus between the enslavement of Africans and issues on language and communication.
\end{abstract}

\section{Keywords}

Language; Slave trade; Historiography on slavery.

Recebido em: 25/1/2017

Aceito em: 13/12/2017 


\section{Diversidade e incomunicabilidade}

[...] e daí começam a correr as novas e estendidas províncias da Etiópia ocidental, várias em sítio, em linguagem e trato, mas de uma só cor dos homens (são todos negros) que à indústria do grande infante D. Henrique deve este reino. Nessas se contava a cidade de S. Jorge da Mina, praça de grande utilidade, pelo resgate contínuo de muito ouro. [...] Contavam-se também a ilha de S. Tomé, próspera por infinito açúcar, com os reinos de Congo e outros vizinhos, ricos por muitas vias, mas principalmente por serem como são fonte perene de inumeráveis escravos (Frei Luís de Sousa, Annaes de Elrei Dom João Terceiro 1844, p. 29).

Minha filha cursava o quinto ano e voltou de um passeio escolar a uma fazenda de café no Vale do Paraíba contando uma das histórias que ouviu. Um grupo caracterizado como "descendentes de escravos", ao iniciar sua apresentação, narrou que os escravos não falavam a mesma língua e que, por isso, teriam inventado uma forma para se comunicar entre si e com independência do senhor: o jongo. Essa afirmação da inventividade e autonomia escrava, se por um lado é inovadora por apontar os escravizados como sujeitos da história, por outro lado parte de um lugar-comum impreciso, que aponta a diversidade de línguas faladas pelos africanos trazidos para o Brasil como um empecilho para sua comunicação. Por ser tão pregnante na memória social e na historiografia, discutir esse lugar-comum é um bom começo para refletir sobre a dimensão da linguagem na formação da escravidão africana no Atlântico.

Contraponto dessa memória, a epígrafe acima, do cronista do rei D. João III (1521-1557), sugere que nas décadas iniciais da exploração da costa ocidental africana, a perspectiva portuguesa não tomava a diversidade de línguas como mais importante que a cor negra, que a todos igualava, nem como obstáculo para a obtenção das riquezas para o Reino - o ouro, o açúcar, os escravos.

O conceito de tópos pode ajudar a entender esse misto de lugar-comum, imaginário, memórias difusas, conteúdos recorrentes que se reproduzem sem necessariamente corresponderem a fundamentos históricos precisos. Tornamse pontos de partida para afirmações e explicações de diferentes regimes discursivos. No campo da historiografia, José Honório Rodrigues aponta uma política colonial que estimularia a diversidade de línguas, embora não apresente referências mais específicas para o que afirma e nem questione a eficácia dessa política: "Foi política colonial portuguesa variar o mais que pudesse a composição da gente africana que trazia para o Brasil. Assim evitavam sua unidade, pela diversidade de língua e os mantinham submissos" (RODRIGUES 1983, p. 29).

No campo da historiografia linguística, Antonio Houaiss, apesar de atentar para as formas de comunicação travadas pelos africanos, para a convivência entre códigos linguísticos distintos e para a importância das línguas gerais, pontos que apontam para a complexidade da questão da comunicação no contexto da escravidão no Brasil, também reproduz o tópos da separação linguística como uma política senhorial, afirmando que a "mistura de línguas africanas, que as enfraquecia relativamente, começava nos portos e postos negreiros da África". E continua: "O fato é que aqui chegados, eram separados, de modo que não 
ficassem juntos nem por línguas, nem por etnias, nem mesmo por famílias, a fim de serem quebrados nos seus eventuais ímpetos de rebeldia" (HOUAISS 1985, p. 71 e 72). Houaiss tampouco apresenta uma referência específica para essas afirmações. Alguns autores recentes continuam a retomar a "política de multiplicidade" como marca da história linguística do Brasil, invariavelmente sem uma referência documental consistente. ${ }^{1}$ Em buscas já realizadas na legislação colonial, bem como em registros de autoridades coloniais, como o Conselho Ultramarino, não se identificou nenhum registro que corroborasse a existência de uma política intencional de separação linguística dos africanos a serem traficados e escravizados no Brasil. ${ }^{2}$

Entre os clássicos da historiografia imperial, Francisco Adolfo Varnhagen, constrói uma imagem um pouco diferente, mas com um elemento comum. Esse historiador não falava em uma política explícita de separação, como nos casos mencionados acima, mas na incomunicabilidade a que estariam limitados os africanos: "Sem identidade de língua, de usos e de religião entre si, só a cor e o infortúnio vinham a unir estes infelizes, comunicando-se na língua do colono, estrangeira a todos, e por isso sempre por eles cada vez mais estropiada [...]" (VARNHAGEN 1975, p. 221).

Trata-se, assim, tanto de uma afirmação recorrente, sem referências documentais, sobre a existência de uma política explícita de separação de etnias e línguas, como de um imaginário da diversidade como impossibilidade de comunicação. As duas variações, aliás, são coerentes com o imaginário senhorial, uma vez que quanto menos comunicação houvesse entre os escravos, mais fácil seria a manutenção da ordem escravista; ${ }^{3}$ ora, isso dista muito de corresponder exatamente a uma prática intencional e sistemática. Neste artigo, procurarei concentrar esses questionamentos no contexto do tráfico atlântico, etapa importante para, em outra oportunidade, fazer a investigação acerca das políticas linguísticas relacionadas à escravidão africana no Brasil.

Para reavaliar a ideia de que a diversidade de línguas dos africanos seria um empecilho para a comunicação nas Américas, alguns questionamentos se impõem. Primeiro, em termos dos projetos: os diferentes agentes do tráfico, incluindo toda a gradação de europeus e africanos envolvidos no processo, de fato levaram em conta determinadas características linguísticas dos povos que eram alvo das capturas, guerras ou outras formas de abastecimento do tráfico? Havia

\footnotetext{
1 "Deve-se lembrar que o número de escravos pode não equivaler ao número de falantes, e a política de multiplicidade linguística, gerada pela prática de evitar concentrações de escravos de uma mesma origem, unida ao incentivo às hostilidades já existentes, desde a África, entre as etnias, foram eficazes no aculturamento dos homens cativos" (CALLOU 2015, p. 78). Callou faz uma ampla discussão das questões que atravessam a história do português no Brasil, apontando a complexidade de situações, mas, para o caso específico da diversificação dos escravos como política, não apresenta uma referência.

2 Nada com esse teor consta na compilação de leis relativas à escravidão (LARA 2000). Na Lei de 18 de março de 1684, na qual se estipulou uma série de medidas relativas ao embarque e transporte de escravos nos navios que saíam de Angola e em relação ao número de escravos de acordo com a embarcação, agasalhos, mantimentos, aguadas, remédios etc., não há nenhuma observação acerca da língua, seja quanto à necessidade de intérpretes, seja em relação à diversificação linguística (CARTA DE LEI 1684).

3 Um estudo crítico sobre a influência da visão senhorial na historiografia, bem como da relação do domínio senhorial com as questões linguísticas e étnicas é o artigo de Lara (2002). Diferentes historiadores (SLENES 1992; ABREU 2014; LIMA 2012; 2015) vêm investigando as práticas de comunicação de escravos africanos no Brasil e criticando o imaginário senhorial.
} 
mesmo uma política de separação linguística nos navios? Ou outras formas de se lidar com a questão da comunicação? Pode-se localizar uma política colonial em relação a esse tema? Não seria essencial evitar generalizações e levar em conta determinadas situações específicas de acordo com as origens étnicas dos escravos, as rotas e diferentes fases do tráfico? Segundo, vale questionar a eficácia desses projetos: para além da suposta divisão estimulada por autoridades, traficantes, senhores, teria essa condição levado a uma dificuldade na comunicação entre os indivíduos escravizados? Como os diferentes povos e agentes africanos se colocaram diante disso? Como se dava a intercomunicação entre esses envolvidos? Como atuaram os diferentes mediadores e intérpretes?

\section{Entender a língua do outro}

O tópos diversidade de línguas e incomunicabilidade deve estar arraigado em um preconceito fundado na própria história do paradigma nacionalista, em que se toma como correspondentes perfeitos uma língua e uma nação e se apagam diferentes situações de multilinguismo e de alternâncias entre códigos que marcam as relações sociais e culturais. As fronteiras de um Estado nacional não se confundem com as fronteiras linguísticas, senão à custa de ações específicas e constantemente repetidas para que tal uniformização se atualize, em um suposto quadro de estabilidade e coerência (GUISAN 2009, p. 24). A própria noção de unidade linguística deve ser utilizada com cautela, pois as práticas de linguagem são antes relacionais, comportam espaços de continuidade, além de não se referir a territórios específicos como às vezes se supõe. Há uma questão complexa no ato de nomeação e classificação das línguas, tenha essa nomeação objetivos políticos ou científicos. Atribuir um nome a determinada língua é uma operação que lida com identidades e fronteiras nem sempre percebidas pelos falantes, como no caso dos povos mandingas, no Mali, cuja prática seria marcada por contínuos linguísticos e para os quais os contatos são mais a regra do que a exceção (CANUT 2001).

Além disso, seria muito interessante levar em conta formas culturais e tradicionais de conhecimento linguístico dos povos envolvidos. Não foram só os jesuítas, capuchinhos e demais missionários que investiram em conhecer a língua do outro, atuando assim como agentes essenciais das alianças e interesses europeus em regiões da África. Povos conhecem as línguas de outros povos. Um exemplo contemporâneo desse conhecimento linguístico tradicional, forjado nos ambientes multilíngues, é dado pelo escritor fula Hampaté Bâ, do Mali. Desenhamse ali, claramente, outras experiências sobre a diversidade linguística:

[...] levei pouco tempo para conseguir me exprimir em francês. Isto não tem nada de espantoso quando se pensa que a maior parte das crianças africanas, vivendo geralmente em ambientes onde coabitavam diversas comunidades étnicas (em Bandiagara havia fulas, bambaras, dogons, hauçás...), já eram mais ou menos poliglotas e habituadas a absorver uma nova língua com tanta facilidade quanto uma esponja se embebe de líquido. Na falta de método, bastava-Ihes passar algum tempo no meio de uma etnia estrangeira para aprender a língua - o que aliás ocorre até hoje (HAMPATÉ BÂ 2003, p. 228-229). 
Povos africanos investiam em figuras chave da dinâmica de sua relação comercial, de vassalagem, de aliança ou de guerra com os outros povos. Os intérpretes eram muito valiosos, sendo a função associada a prestígio e poder. Intérpretes africanos foram vendidos aos primeiros portugueses que chegaram ao Senegal (CURTO 2009 p. 27).

De acordo com Claudio Pinheiro, a definição de técnicas de comunicação, como a formação dos "línguas" (intérpretes), e mais tarde também a elaboração de gramáticas e dicionários nas línguas locais foram essenciais na expansão portuguesa, compondo um lugar importante no aparato da expansão colonialista. Nas primeiras viagens à costa da África, formas de comunicação com os nativos eram buscadas:

\begin{abstract}
Alguns dos diversos navegantes que estiveram entre os primeiros a explorar a costa africana no século XV (entre eles Francisco Cadamosto, Gomes Eanes de Zurara, Diogo Gomes de Sintra) reiteram em seus relatos que a continuidade da exploração do périplo africano dependia diretamente da compreensão das línguas que eram ali faladas (PINHEIRO 2008, p. 32-33).
\end{abstract}

Os intérpretes nativos eram formados em Portugal, onde aprendiam português e eram batizados. Ou, então, eram usados os degredados, deixados nas regiões africanas para aprenderem as línguas e localizados em viagens posteriores. Uma terceira via de contato era criada através dos missionários, que investiam no aprendizado das línguas locais. Um incremento importante dessa investida colonial começou a ocorrer no século XVI, com a chamada revolução da gramatização (AUROUX 2009), quando passaram a ser produzidos dicionários e gramáticas das línguas locais, servindo de instrumentos mais eficazes para o domínio linguístico de portugueses, espanhóis, franceses, ingleses, dinamarqueses etc. Todo um investimento foi feito nesse sentido, que implicava a construção de uma representação gráfica para essas línguas, a definição de sua gramática, a elaboração e impressão de dicionários de uma vastidão de línguas da África, Ásia, América. Definidos por Pinheiro como "livros de tradução", formando um gênero característicamente moderno, sua operação básica implicava em reduzir diversidades locais a categorias etnocêntricas de compreensão do mundo. A codificação das línguas visava não apenas a sua difusão, mas também a transmissão de padrões de comportamento adequados.

Buscando ampliar a disponibilidade dos intérpretes nativos, os portugueses prometiam a alforria àqueles que conseguissem quatro escravos para substituílos, forjando, assim, um sistema de formação. Mas, apesar do prestígio,a de intérprete era uma função arriscada, uma vez que quem desempenhava essa função era o primeiro a se aventurar nos contatos iniciais e negociações com os povos locais. Casos houve em que os intérpretes se tornaram eles próprios agentes do tráfico. No caso particular do Congo, em que havia mais claramente um projeto de alianças e doutrinação cristã, os agentes intermediários eram incentivados também a usar a escrita (CURTO 2009, p. 27-56). Eram ainda usados como instrumentos facilitadores da conversão. Curto mostra ainda como 
se deve considerar não só as relações oficiais, mas também as práticas de grupos locais ligados ao tráfico, como os lançados, que criaram na prática suas formas de comunicação (CURTO 2009, p. 32). Além do uso dos intérpretes, a tendência geral foi, antes, a de aprender as línguas locais que impor o uso do português, algo que por muito tempo não passou de um ideal (VANSINA 2001; HEINTZE 2005). A expansão das línguas europeias foi um processo histórico com periodizações específicas. A princípio, língua e império formariam um par, a unidade da língua evocando a unidade do reino, par que traduz a importância da expansão da língua do príncipe na formação dos impérios coloniais na era moderna (ASENSIO 1960, p. 339-413). No entanto, longe de ter sido um processo linear apontando para uma "vitoriosa" expansão da língua portuguesa e da religião cristã, essa experiência foi marcada por práticas locais de comunicação preexistentes. Em suma, é essencial levar em conta os saberes locais sobre como lidar com as línguas do outro.

\section{Cadornega e os caminhos da guerra, do tráfico e da comunicação}

Para melhor articular os projetos coloniais às formas de vivência e comunicação específica entre os diferentes grupos linguísticos, iremos analisar algumas narrativas produzidas por europeus envolvidos com o tráfico em distintas regiões e épocas. Além de operar a leitura crítica dos relatos de época, pretendemos também avaliar como a historiografia tem lidado com essa questão.

Começamos pela copiosa narrativa de Cadornega sobre a presença portuguesa em Angola no século XVII, História geral das guerras angolanas (CADORNEGA 1972). Tendo atuado como oficial militar, o português Antonio de Oliveira Cadornega (1623-1690) se apresentava como "cidadão" de São Paulo de Assunção de Luanda, cidade onde se refugiara da perseguição aos cristãosnovos e onde viveu por mais de quarenta anos. Sua extensa obra historia os governos, os povos, as regiões e acidentes naturais. O vocabulário local impregna o seu texto: quilombo, jagas, banza, macota, songos, calunga, embaca. O termo "quilombo", muito usado para falar da rainha Ginga e do Jaga Casangi, pela relevância que adquiriu na história do Brasil, evidencia como a perspectiva da história atlântica é decisiva para avaliar esses trânsitos linguísticos, muito mais do que circunscrever a questão ao espaço territorial da colônia americana, como propõe Alencastro (2000). O relato de Cadornega deixa a impressão de que em função da guerra preta, isto é, dos intermediários africanos que obtinham escravos através de guerras, e do comércio de escravos e mercadorias que antecedeu o tráfico atlântico, as questões linguísticas eram contornadas e não se impunham como uma dificuldade maior.

O quilombo poderoso do nosso Jaga Casangi que, pelo muito que domina seu poder, se pudera chamar Rei e Imperador, consta todo ele de gentio Jagas, que não vivem mais que da guerra, tendo muitos macotas com seus songos ou trocos de que são senhores absolutos, reconhecendo só a Casangi como sua cabeça e senhor [...] (CADORNEGA 1972, p. 215). 
Passagens do relato permitem pensar sobre as formas de comunicação e de circulação, bem como sobre as perspectivas mútuas sobre o impacto do tráfico. A partir dos jagas, os portugueses de Luanda ficaram sabendo que existia um povo no sertão, chamado donges, que teria conhecimento da presença dos brancos no outro lado do continente, a milhares de quilômetros dali.

Também dão notícia aos próprios Jagas conquistadores que no íntimo do sertão, em que gastam três meses no caminho, onde têm chegado com suas conquistas, há uma casta de gentio, a que chamam os Donges, gente de muito valor, onde haviam perdido três empresas de seus exércitos e sido rotos e desbaratados por eles; que de algum deste gentio souberam em como muito além deles e de suas terras havia mar, ou calunga, que assim Ihe chamam na sua língua, onde passavam uns lungos grandes e havia uma fortaleza de gente branca, a que chamavam embaca lungos grandes, e aputo chamam eles às nossas naus; e aputo de Portugal, e a embaca deve de ser sem dúvida a nossa fortaleza de Mombaça; e não se pode muito duvidar porque este dilatado sertão lá vai demandar, e poderá ser este gentio belicoso, a que chamam Donges, princípio da Cafraria dos rios de Quama (CADORNEGA 1972, p. 220).

Assim, a notícia da presença de europeus, que atravessava rios e povos, fazia surgir também entre os africanos um novo vocabulário e um esforço conceitual para reagir a tal presença. Digna de nota nesse trecho é ainda a palavra "calunga", que no Brasil adquiriu uma história própria na memória afrodescendente (SLENES 1992, p. 48-67).

A preexistência das rotas de comércio de variadas mercadorias, incluindo escravos, foi decisiva no estabelecimento das redes que alimentaram o tráfico atlântico (ALENCASTRO 2000; THORNTON 2004; RODRIGUES 2005). De forma correlata, em termos linguísticos, esse contexto é muito mais marcado pela força dos códigos locais do que por um suposto processo de expansão da língua portuguesa, expansão essa muitas vezes superdimensionada ou imprecisa em termos de periodização. A língua portuguesa não se assentou na África como uma língua unificada de uso amplamente compartilhado, mas na forma de jargões simplificados, formas pidiginizadas, apropriações. A lógica e o interesse europeus não se construíram sem se articular a lógicas e interesses africanos. No caso específico da diversidade de línguas dos africanos apreendidos pelas redes do tráfico, isso se devia ao próprio constrangimento das formas de obtenção desses contingentes: "Muito mais por motivos decorrentes da segmentação do trato sertanejo do que por razões de segurança dos escravistas, os deportados provinham quase sempre de áreas distintas umas das outras" (ALENCASTRO 2000, p. 147-148).

No relato de Cadornega há um episódio em que a língua de um povo foi tomada como estorvo para sua mercantilização. Seria um grupo de capturados levados a Luanda e que, pelos seus hábitos "selvagens" e sua língua enigmática, teria sido desprezado por todos os agentes do tráfico e enviado de volta à sua terra. Eles usariam a língua coissã, de "estalos". ${ }^{4}$ No governo de André Vidal de

\footnotetext{
${ }^{4}$ As línguas coissãs, também designadas como bosquímano ou hotentote, são ou foram faladas em regiões da
} 
Negreiros, em 1664, um homem chamado José da Rosa liderou uma expedição pela costa. Esta fazia parte da longa busca de uma ligação entre Angola e Moçambique, só alcançada séculos depois. O chefe da expedição, a determinada altura, resolveu

[...] trazer gentio daquela paragem, que se não entendia nada do que falava; e a fala como de estralo, gente como selvagem, que bem o demonstravam assim em comerem a carne, e peixe, e milho cru, e por acenos, só se entendia deles alguma coisa, os quais os se mandaram pôr outra vez em suas terras, à custa de quem os trouxe, sem os haver comprado, nem resgatado, o que bem se demonstrava em tanta distância de sertão, haver mais províncias de diferentes línguas e costumes, e não ser só a de o Hila [Huila] (CADORNEGA 1972, p. 174-175).

Alencastro, que também analisa esse episódio, argumenta sobre a necessidade de uma mínima mediatização cultural para operar a dessocialização imposta pelo escravismo. Ou seja, sem um domínio linguístico mínimo, o tráfico não se sustentaria. Ainda Alencastro, ao falar de um lançado na Senegâmbia, no século anterior, faz-nos pensar que mais importante do que transitar e compreender a língua dos próprios capturados seria manusear a língua das chefias e agentes do comércio. Conhecido como Gana-Goga, "que fala todas as línguas", o lançado alentejano João Ferreira entrou no sertão, incorporouse ao reino fula e se casou com uma princesa, tirando vantagem disso para negociações que alimentariam os interesses escravistas (ALENCASTRO 2000, p. 48). Assim, a plasticidade desse aventureiro, sua capacidade de negociação, devia valer, sim, mas não exatamente para as vítimas da rede do tráfico, isto é, para os próprios cativos.

O caso coissã, como notou Alencastro, é essencial para notar os limites da comunicação em um contexto de escravização de povos. De resto, notamos que a diversidade de línguas não era em si mesma um obstáculo para a montagem das redes do tráfico. Para superar as abstrações e explicações gerais é necessário pensar em situações específicas. A área abarcada pelo contexto de Cadornega, grosso modo, incluía-se na grande região marcada pelo tronco linguístico comum banto, cujas línguas têm semelhanças estruturais e uma proximidade lexical, daí a possibilidade de intercomunicação entre alguns grupos (PETTER 2014). Além disso, eram usadas línguas de comércio e contato, dentre as quais o quimbundo, que teve uma grande importância na história da presença portuguesa em Angola (VANSINA 2001; FERREIRA 2012; LIMA 2017).

Em vez de uma política de separação de escravos africanos por meio da língua, no final do século XVII registrava-se uma preocupação mais urgente. Algum tempo depois de ter sido decretada a necessidade de um capelão para a "salvação" dos escravos em toda embarcação, o rei de Portugal, D. Pedro II, definiu que em cada navio houvesse "capelães práticos nas línguas do sertão" ou que, quando não houvesse capelães, "se procurasse tal forma no modo de

Tanzânia, Angola, Zâmbia e Zimbábue. Caracterizam-se pelo uso de diferentes cliques e estalos produzidos na boca, os quais representam fonemas particulares, dificilmente decodicáveis pelos falantes de outros grupos linguísticos (BONVINI; BUSUTTIL; PEYRAUBE 2011, p. 225). 
embarcar os negros que fosse a carregação em cada embarcação, daqueles que o capelão soubesse a língua"; ao que o cabido de Angola responde que seria regra impossível de observar,

porque do dilatado sertão daquele Reino, vem de cada parte dele, pouca quantidade de escravos, com que se faz a carga de cada navio, porquanto se se estivera esperando viessem só de uma terra, seria impossível sair cada ano um pataxo, o que era em grande prejuízo do comércio (CONSULTA 2013).

A solução seria estimular que houvesse capelães nativos que usassem das línguas do sertão ou, como já se fazia, que se recorresse aos "ladinos que sirvam de intérpretes". ${ }^{5}$ A resposta da autoridade religiosa local nos aponta, portanto, que, em vez de separar as etnias em cada navio, teria sido mais útil que houvesse um código comum, o que na prática acabava por se revelar algo impossível. Consequentemente, se havia diversidade de línguas, essa era uma condição que se impunha e não algo programado.

Isso não nos deve fazer supor, bem entendido, que a diversidade impedisse, de fato, a intercomunicação. Uma visão local mostra a importância da comunicação feita na língua atualmente designada como quimbundo entre povos diferentes. Segundo um testemunho de 1686, um capelão que não entendesse a "linguagem ambunda, que é a mais fácil de todas as daquele gentio" seria "consequentemente ignorante da dos Congos, Munjolos, Muviris e Benguelas, de cujas nações consta a carga dos navios que vêm ao Brasil" (CARTA A EL REI 2013). Dito de forma mais direta, um capelão que soubesse quimbundo poderia também se comunicar com aqueles outros povos.

\section{William Smith e os linguistas do tráfico}

Passemos agora a contextos mais amplos. Jaime Rodrigues, em sua análise sobre os diferentes agentes ligados ao tráfico de escravos, com foco no período de 1780 a 1860, traz informações e reflexões valiosas para pensarmos a questão da linguagem. Diferentes mediadores, tais como o intérprete e o "gritador", incluiam-se entre os funcionários que atuavam nos barracões (locais onde se acumulavam os cativos antes do embarque). Sua tarefa era cuidar da conexão entre os escravistas e os povoados próximos. No espaço dos navios negreiros, os africanos não estavam apenas entre os cativos, mas também na tripulação, pois eram fundamentais para estabelecer a comunicação: "a presença de tripulantes africanos nos navios negreiros poderia se dar pela necessidade de um elo de comunicação entre os demais tripulantes e os cativos, para saber o que murmuravam os escravos encarcerados no porão e prevenir revoltas" (RODRIGUES 2005, p. 68).

O mais interessante na perspectiva de Jaime Rodrigues é justamente apontar como formas de comunicação entre marinheiros e escravos eram constantes, indo além de projetos de domínio e disciplina. "Em todos os portos onde a escravidão

\footnotetext{
${ }^{5}$ Ver referência anterior.
} 
africana existia, era impossível controlar totalmente outras atividades que envolvessem escravos e marinheiros" (RODRIGUES 2005, p. 205-206). Além dos navios, em inúmeros locais como chafarizes ou pontos de venda de alimentos, marinheiros e escravos de diferentes origens se reuniam para trocar notícias, experiências, linguagens e canções que atravessavam o Atlântico.

O relato de William Smith traz alguns interessantes aspectos da perspectiva britânica sobre as formas de comunicação com e entre africanos. Smith integrou uma expedição enviada pela Royal African Company para mapear a Costa da Africa, entre Gâmbia e Ajudá (Whidah), em 1726. O navio Bonetta parava em diferentes pontos do litoral, e a incubência de Smith nesses locais era a descrição dos rios, a avaliação das possibilidades de comércio, das condições de fortes e feitorias e, por último, das formas de contato com os povos locais. A essa altura, o tráfico britânico, apoiado não só por comerciantes como também pela monarquia, parlamento e aristocracia, enviava africanos cativos para as regiões de colonização britânica e também para a América hispânica, pois havia obtido o direito de asiento em 1713.

Alguns dos episódios narrados por Smith envolvendo tensões, conflitos e choques culturais entre os povos locais e os britânicos apontam diferentes usos dos códigos linguísticos. Determinados africanos falavam inglês e se colocavam em posições intermediárias e ambíguas entre os interesses de uns e outros. No início da expedição, um grupo de nativos se assustou os seus instrumentos de agrimensura dos europeus e começou um movimento de reação aberta que apavorou Smith. Ele interroga, então, os remadores de barco, escravos da companhia britânica que falavam inglês, os quais dão como motivo de sua revolta o medo de serem enfeitiçados pelos europeus e seus instrumentos (SMITH 1745, p. 16).

Em um episódio mais festivo, após ter chegado à região do rio Gâmbia, Smith assiste a um discurso do rei

[...] o rei fez um breve discurso, traduzido para mim pelo seu irmão mais novo, que para receber a melhor educação havia morado no castelo, e se dava bem comigo. Ele me disse que o rei fez aquele discurso para o seu povo na audiência do governador Rogers, que entendia a sua língua, e que o rei disse "é muito bom que o homem negro ame o homem branco, e não o machuque, mas antes faça comércio com ele, pois o navio do homem branco traz os bens mais preciosos e os melhores licores para o país do homem negro" (SMITH 1745, p. 21). ${ }^{6}$

Ali, assim como os remadores de barco que falavam inglês, o próprio irmão do rei se dedicava a entender os ingleses e buscar boas condições de comércio. Afinal, os intérpretes eram figuras ambíguas, nas quais tanto europeus como africanos iriam investir. Uma situação tensa vivida por Smith ao passar na

\footnotetext{
${ }^{6} \mathrm{~A}$ tradução das citações em língua estrangeira são de minha autoria. No original: "(...) the king made a short speech, which was interpreted to me by his youngest Brother, who for his better Education resided mostly at the castle, and was very well acquainted with me. He told me, that the King made that speech to his own people in the hearing of Governor Rogers, who understood the Language, and that the King said, "It was very good for Black Man to love White Man, and not hurt, but make trade with him; because a White man's ships bring all the good things, and strong liquors into Black man's country".
} 
região de Serra Leoa evidencia essa ambiguidade. O rei sherbro ${ }^{7}$ começou um movimento contra os ingleses em função do imposto devido que Ihes daria direito de comerciar no local (cole). A certa altura, tendo os ingleses se refugiado no navio ancorado, um grupo de locais se reúne na costa. Os ingleses abrem fogo, e, além de um africano morto, acaba ferido o "linguista da Companhia", chamado Antônio, africano a serviço dos ingleses, que acaba tomado como um traidor pelos britânicos. Antonio dá sua versão dos fatos: "Isso é verdade, amo. Eu tenho duas línguas. Língua para o branco e língua para o negro. Eu merecia morrer, mas os brancos não devem matar os negros, mas serem amigos deles" (SMITH 1745, p. 75). ${ }^{8}$

Antônio acaba dizendo que estaria em missão de paz, enviado pelo rei Sherbro, que teria se enganado ao achar que os ingleses não tinham pagado o imposto. Os escravistas se reúnem para deliberar, ponderando que não se podia ter confiança no intérprete, e se retiram da região.

Vale a pena considerar o uso do termo linguist, nas referências em língua inglesa, com essa acepção que mescla funções de intérprete, emissário ou secretário dos chefes locais. Embora no escopo deste trabalho não possamos fazer uma análise exaustiva, encontramos algumas vezes o termo linguist para aqueles que são chamados, entre o povo fante, de okyeame poma, que seriam o porta-vozes reais dos governantes, atuando como intermediários e conselheiros, marcados pelo domínio da linguagem, uso de provérbios e ostentando seus cetros. ${ }^{9}$

Seria interessante recuperar em que ponto da história da África o termo linguist passa a traduzir, para os agentes de língua inglesa, essas diferentes funções que envolviam o domínio da linguagem. Joan M. Fayer fez um estudo detalhado sobre os intérpretes africanos no contexto das relações com os britânicos e observou esse termo nas crônicas históricas dos séculos XVII e XVIII na região da África Ocidental (FAYER 2003, p. 281-295).

Em contexto posterior, no século XIX, na região de Cabinda, registra-se o termo linguester ou linguister para designar agentes centrais que operavam a intermediação entre as chefias africanas locais e o comércio atlântico, que tinham entre seus atributos o de serem intérpretes, como aponta Marcos Abreu. Analisando o relato de Joachim John Monteiro, Angola and the River Congo (1875), o historiador Abreu destaca o comentário de que os linguisteres do Congo seriam embusteiros e mentirosos, jogando com seu poder linguístico em benefício próprio. Um dos embustes seria, por exemplo, anunciar um valor em quicongo e outro para os brancos, embolsando a diferença. Monteiro atribui a origem da palavra

\footnotetext{
7 O povo sherbro, nome também da língua relacionada, vive na Serra Leoa, onde somam hoje 135 mil falantes (www.ethnologue.com). Desde o início do século XVIII o reino esteve envolvido com o tráfico de escravos, negociando com os britânicos.

${ }^{8}$ No original: "This very true, Master! I have two Tongues; tongue for white man and tongue for black man, I deserve to die, but I came that White men should not kill black but be friends".

${ }^{9}$ Um desses cetros está exposto no National Museum of African Art, em Washington: Linguist Staff (okyeame poma). Povo fante, Gana. Meados do século XX. Há um link disponível para a peça em: <http://africa.si.edu/ collections/view/objects/asitem/search\$0040/0?t:state:flow=72ac3541-f0f9-44da-a571-217929c6436c>. A palavra okyeame significa "porta-voz", "intérprete", "interlocutor", "embaixador" e "advogado". Uma análise sobre a complexidade dessa função, as exigências rituais e de linhagem para seu cumprimento entre os Obo e demais povos Akan pode ser encontrada em: <http://www.scn.org/rdi/kw-stf.htm>. Acesso em: jun. 2016.
} 
ao termo "língua", em português, que há séculos era sinônimo de "intérprete" (ABREU 2012, p. 62-63). Acrescente-se que no inglês atual linguist é empregado não só para designar o especialista em linguística, mas qualquer um que fale línguas estrangeiras, sentido registrado já no século XVI.10

Smith insistia em uma perspectiva sobre os povos africanos segundo a qual aquilo que ele entendia como uma diversidade de línguas supostamente levaria a uma ininteligibilidade mútua, vantajosa para os negócios escravistas. Essa seria, segundo Smith, uma característica da Costa do Ouro, nas proximidades da fortaleza de Axim (atual Gana). Indo além da "surdez seletiva" de Smith, que fazia com que ele entendesse só o que valia a pena para seus interesses, vale a pena comentar que a região era marcada pelas línguas do grupo gbe, como aja, ewe, fon, gen e gun, que formam, segundo os especialistas contemporâneos, um continuum linguístico com variedades com características gramaticais e lexicais comuns (KLUGE 2007). ${ }^{11}$ Trata-se de um conjunto de línguas bastante importante ao considerarmos a história do tráfico para o Brasil. As línguas gbe constituem a base da língua geral da Costa da Mina, documentada em Minas Gerais, na primeira metade do século XVIII (PEIXOTO 1945) e usada também no Rio de Janeiro, Bahia e Maranhão.

Mesmo na região da Gâmbia, onde Smith também aponta uma incomunicabilidade entre os diferentes grupos linguísticos como um elemento vantajoso para os europeus, com a condição de se separarem os cativos nos navios, essa visão não se sustenta diante do fato de que lá se falavam línguas como mandinga, fula, serer, wolof, ${ }^{12}$ línguas de povos que mantinham um intenso comércio e que não se restringiam a locais específicos, sendo faladas em diferentes regiões. Assim, mesmo que suas línguas fossem diferentes, essa condição não impossibilitava a comunicação e a troca entre esses povos.

Um outro elemento do relato de Smith sobre o qual vale a pena chamar a atenção trata de uma observação sobre a ausência da escrita na região de Axim. "Eles não sabem ler nem escrever, e portanto pouco pode ser conhecido sobre sua Antiguidade e História. Tudo aqui é incerto e tradicional" (SMITH 1745, p. 111). ${ }^{13}$ Smith entrou em contato ali com uma narrativa mítica interessante sobre o poder da escrita dos brancos:

Todos os povos nativos dessa Costa acreditam que há um Deus verdadeiro, seu criador e de todas as coisas. Eles dizem que no começo Deus criou o Negro e também o Branco; que Ihes ofereceu então duas dádivas, o ouro, e o conhecimento da arte de ler e escrever, dando aos Negros o poder

\footnotetext{
10 New Oxford American Dictionary (2010). Um dicionário de uso geral define linguist como "one skilled in languages" (alguém versado em línguas). Webster's Practical Dictionary. New York: Grossete \& Dunlap, 1932 , p. 426.

${ }_{11}$ As línguas gbe são faladas numa área que abrange o rio Volta inferior (ao sul de Gana), o Togo, Benim, Nigéria Ocidental e o curso inferior do rio Weme. Dentre elas, o ewe é falado atualmente por cerca de 3 milhões de pessoas, e há uma língua padrão escrita desenvolvida no século XIX (BONVINI; BUSUTTIL; PEYRAUBE 2011, p. 79).

12 O wolof tem hoje de 8 a 10 milhões de falantes, no Senegal, Gâmbia e Mauritânia e é também uma língua de comunicação. A língua mandinga, que comporta diversos falares, está presente em vários países (Mali, Burkina Fasso, Costa do Marfim, Libéria e outros), também é usada como língua veicular (BONVINI; BUSUTTIL; PEYRAUBE 2011, p. 23 e 33).

13 No original: "They cannot read nor write, by which means as to the knowledge of their Antiquity, History, etc. little is to be learnt, every thing here being uncertain and traditional".
} 
de escolher primeiro. Eles então escolheram o ouro, e os Brancos foram obrigados a escolher o conhecimento das letras. Deus garantiu o pedido dos Negros, mas tendo sido movidos pela Avareza, Deus resolveu que os Brancos deveriam ser para sempre seus senhores e os Negros, seus escravos (SMITH 1745, p. 213). ${ }^{14}$

Nessa narrativa, os homens dali teriam se deparado com o impasse entre escolher a riqueza do ouro ou o poder da escrita. Tendo escolhido o ouro, os negros teriam demonstrado sua avareza perante Deus, e como uma punição por isso, Ihes restaria tornarem-se escravos dos brancos. Além disso, aos brancos só restou escolher a escrita. No entanto, as comuns e recorrentes imagens sobre a generalizada ausência de escrita na África constituem mais um dos estereótipos largamente combatidos por pesquisas de africanistas. Apropriações do poder da escrita ocorreram em diferentes partes. Em análises sobre a cultura escrita entre as chefias ndembu, no norte de Angola, Catarina Madeira aponta como

[...] os africanos, mesmo antes de saberem ler e escrever e de reconhecerem à escrita a função de instrumento de comunicação, foram compelidos a considerar o carácter vinculativo, fixo e perene do que é gravado sobre o papel. Antes de ser instrumento de comunicação, a escrita foi utilizada e apreendida como um símbolo do poder político europeu (SANTOS 2006, p. 81-95).

Essa busca sobre o domínio da escrita é mais uma mostra do potencial de comunicação com o outro por parte dos povos africanos.

\section{Théodore Canot e o comércio como comunicação}

O relato do capitão Theodore Canot (1804-1860), ${ }^{15}$ Captain Canot, or Twenty Years of an African Slaver, que se tornou um negreiro já na década de 1820, apresenta também diferentes situações envolvendo europeus e africanos que nos permitem articular reflexões sobre linguagem e escravidão. Organizado e elaborado por Brantz Mayer, o relato constitui uma tomada de posição sobre a persistência do tráfico em uma época em que novos rumos estavam sendo dados a esse aspecto da história da África e em que o abolicionismo iria se somar à reestruturação das ações imperialistas no continente. ${ }^{16}$ Canot tinha origem francesa e, ainda jovem, após algumas viagens entre Livorno, Boston, Sumatra, Antuérpia, Rio de Janeiro e Havana, parte desta última cidade em uma empreitada escravista na costa da África, mais especificamente no rio Pongo,

\footnotetext{
14 No original: "All the natives of this Coast believe there is one true God, the author of them and all things: They say, that in the beginning God created Black as well as White men; that he having created these two sorts of men, offer'd two kinds of gifts, (214-) viz. gold, and the knowledge of art, reading and writing, giving the Blacks the first Election, who chose gold, and the Whites was oblig'd to take the knowledge of letters; that God granted their request, but being incens'd at their Avarice, resolv'd, that the Whites should for ever being their masters, and they their slaves".

15 O livro foi editado em 1854 por Brantz Mayer, de Baltimore, a partir de relatos e anotações do capitão Canot no contexto das incursões coloniais norte-americanas na África.

$16 \mathrm{Um}$ dos aspectos desses novos rumos seria a desestruturação da relação entre os agentes africanos ligados ao tráfico e os interesses escravistas na América. Segundo um texto pioneiro de Alberto da Costa e Silva, o abolicionismo britânico buscava neutralizar interesses africanos (dentre os quais aqueles ligados ao comércio de escravos) de forma a reconstruir formas de exploração econômica no continente, como, por exemplo, a agricultura de exportação (SILVA 2003, p. 11-52). O artigo é de 1976.
} 
atual Guiné. Na localidade de Bangalang, conhecida feitoria controlada por ingleses, foi contratado por Mongo John, filho de um traficante de Liverpool com uma nativa. Mongo John fora educado na Inglaterra, mas, com a morte do seu pai, e provavelmente pressionado pela campanha abolicionista já ativa nesse período, volta e assume sua função na terra natal.

As passagens em que Canot descreve as ações de comércio de Mongo John são bastante elucidativas das relações de negociação e tensão que o trafico envolveu. Mongo John era reconhecido pelas tribos de fulas e mandingos do interior, que o chamavam de rei e ofertavam peças para o seu harém. Nas empreitadas, era costume Mongo John enviar corredores (runners) até Serra Leoa e Goreia para anunciar sua intenção de comércio. Em troca de tecidos vindos da América, França e Grã-Bretanha, ele recebia peles, cera, dendê, marfim, ouro e escravos, que revendia aos espanhóis e portugueses.

O traficante conta que no início de sua estada, não falava o sussu ${ }^{17}$ (CANOT 1854 , p. 157), mas que ainda assim tinha oportunidade de se comunicar, por exemplo, com uma das mulheres do harém de Mongo que sentiu simpatia por ele: "filha de uma mulata e um branco, nasceu no assentamento de Serra Leoa, e aprendeu nossa língua com muito mais fluência do que era comum entre os de sua raça" (CANOT 1854, p. 158). ${ }^{18}$

Passado algum tempo, Canot se sentiu familiarizado com os interesses de Mongo e a lógica do comércio da região, mas dizia que ainda não sabia falar a língua local. O rei designou para ele um intérprete, que o auxiliava nas transações envolvendo arroz, marfim, dendê e provisões domésticas, reservando para seu próprio controle o negócio de escravos e ouro. Quando se tinha notícia da iminente chegada de caravanas ao litoral, emissários (barkers) se antecipavam, levando presentes para propiciar bons negócios: "Os emissários são cavalheiros de cor, de fala fluente e consciência flexível" (CANOT 1854, p. 165-166). ${ }^{19}$

Aos poucos, Canot aprendia, observando Mongo, a negociar escravos. Até que três meses depois de estar em Bangalang, já entendia a língua bem o bastante para dispensar o intérprete, se tornando um traficante independente. Essa trajetória tinha sido seguida de forma semelhante pelo inglês Joseph, que também havia servido ao africano durante um ano, até o momento em que se considerou suficientemente informado sobre o comércio e a língua da região (CANOT 1854, p. 182 e 186). A partir de então Canot fez diversas viagens, abastecendo sobretudo o mercado de escravos cubano. O tratamento dispensado aos seres que carregava era descrito por ele seguindo princípios de aproveitamento do espaço, de regras de higiene, ventilação, alimentação e de momentos de descontração que iram contribuir para a segurança da empreitada: "Nas tardes de clima ameno, permitia que homens, mulheres, garotas e garotos se unissem nas melodias africanas, acompanhadas pelo tan-tã improvisado com

\footnotetext{
17 O sussu tem atualmente cerca de um milhão de falantes e é uma das línguas nacionais da República da Guiné, estando presente também na Serra Leoa (www.ethnologue.com).

${ }^{18}$ No original: "This poor girl, the child of a mulatto and a white parent, was born in the settlement of Sierra Leone, and had acquired our language with much more fluency than is common among her race".

19 No original: "Barkers are colored gentlemen, with fluent tongues and flexible consciences".
} 
panelas ou vasos" (CANOT 1854, p. 193). ${ }^{20}$ Não encontrei menções a possíveis estratégias no carregamento de navios de forma a impedir que os cativos se comunicassem. Ao contrário, uma das viagens levou apenas mandingos para Havana, onde eram valorizados por suas qualidades para serviços domésticos (CANOT 1854, p. 205).

Em uma ocasião, o navio de Canot, Estrela, partiu de Ajudá, onde ele negociou com o famigerado traficante Chachá, ou Francisco Félix de Souza, descrito como um mulato nascido no Rio de Janeiro que se instalou no Daomé e que, entre suas qualificações como traficante, incluía a fluência na língua nativa (CANOT 1854, p. 424). Nessa mesma viagem, Canot enfrentou uma revolta no navio que o fez lamentar não ter um intérprete para o "necessário intercurso" com os escravos.

Não havia ninguém a bordo que entendesse uma palavra de seu dialeto. Muitas das reclamações dos negros que poderiam ter sido acomodadas ou contidas de forma satisfatória, se nós compreendêssemos suas línguas e queixas, passaram em silêncio ou foram reprimidas com o chicote. De fato, apenas o açoite era o emblema da disciplina do La Estrela; e no final das contas isso me ensinou uma triste lição (CANOT 1854, p. 425). ${ }^{21}$

Com muito custo controlaram os amotinados, mas o capitão atribui essa vitória ao fato de que no fundo eles não estavam todos de acordo e apenas por isso foram derrotados (CANOT 1854, p. 440). Daí até o final da travessia em Matanzas, quem reinou foi o chicote, o ferro e o terror.

\section{Cannecattim e a superação dos intérpretes}

É significativo concluir esta reflexão com a análise de parte da obra do missionário capuchinho de origem italiana Bernardo Maria de Cannecattim que no início do século XIX produziu uma gramática e um dicionário de quimbundo, escritos em língua portuguesa e publicados em Lisboa pela Imprensa Régia (CANNECATTIM 1804; 1805). Àquela altura, o quimbundo costumava ser chamado língua "bunda". Fechamos assim o artigo voltando a tratar de uma das principais áreas do tráfico de africanos para o Brasil. Trata-se de um obra de gênero distinto das anteriores, uma vez que tem uma relação mais indireta com o tráfico, mas que aponta as transformações históricas na região e que, por ter como foco exatamente o domínio linguístico, traz elementos importantes para entender questões aqui encaminhadas.

Os estudos de Cannecattim são parte de uma série de obras que vinham sendo produzidas particularmente desde o século XVII por missionários capuchinhos, jesuítas e de outras ordens e que tiveram como foco o domínio sobre línguas africanas, especialmente o quicongo e o quimbundo. Trata-se de

\footnotetext{
${ }^{20}$ No original: "During afternoons of serene weather, men, women, girls, and boys are allowed to unite in African melodies, which they always enhance by an extemporaneous tom-tom on the bottom of a tub or tin kettle." ${ }^{21}$ No original: "There was no one on board who understood a word of their dialect. Many complaints from the negroes that would have been dismissed or satisfactorialy adjusted, had we comprehend their vivacious tongues and grievances, were passed over in silence or hushed with the lash. Indeed, the whip alone was the emblem of La Estrela's discipline; and in the end it taught me the saddest of lessons".
} 
dicionários ou vocabulários, gramáticas e catecismos que integram o processo de gramaticalização das línguas do globo (AUROUX 2009), característico da expansão europeia e já mencionado acima.

Um longo percurso havia sido feito desde os primeiros séculos das investidas portuguesas na África, e os textos introdutórios de Cannecattim mostram como, naquele momento, já haveria condições de administrar com mais controle a comunicação, conseguindo independência diante do sempre temível intérprete. Abria-se assim uma era de presença gradualmente mais marcante do português nas relações travadas em Angola, ainda que tal presença tenha demorado décadas para se firmar (AZEVEDO 2015; MARZANO 2014). Naquele momento, os próprios portugueses deveriam se preocupar em assumir o domínio do quimbundo, e, com sua obra, Cannecattim pretendia contribuir para essa empreitada. Tendo vivido vinte anos no "Reino de Angola", ele justifica a utilidade do dicionário pela dependência da religião de uma "Linguagem que seja entendida do Pastor, e do rebanho", e critica o clero, que desconhece a "língua bunda", bem como a ausência de "mestre ou livro" para aprendê-la. O perigo disso seria "[...] sujeitarem-se precisamente ao uso dos intérpretes, pelos quais se persuadem entenderem, e serem entendidos do Povo". Afinal,

Os intérpretes são Negros do País, gente bruta, que ignora da sua própria Língua uma grande parte, e que da Portuguesa apenas sabe os termos mais vulgares, e usuais. Por estes homens, ou por estes brutos, se há de anunciar ao Povo a Doutrina da salvação nos seus Dogmas, e na sua Moral; mas sucede, frequentemente, que uns tais intérpretes, ou não percebem a força, e o verdadeiro espírito das palavras Portuguesas, ou não sabem achar, e escolher na sua Língua termos, que propriamente Ihes correspondam, de que pode resultar o ensinar erros substanciais, assim a respeito do que devemos crer como do que devemos obrar (CANNECATTIM 1804, p. ii).

Como em outras situações analisadas nesse artigo, a tarefa de traduzir não era algo neutro. Ao contrário, era parte da ordem política. No contexto angolano, os tandalas, que assumiriam, entre outras funções, a de intérprete, eram pontos de uma complexa rede de hierarquia política das chefias locais, que envolviam embaixadores, conselheiros e chefes militares (CARVALHO 2010, p. 52). Dispensar os intérpretes seria, assim, evitar o poder desses "brutos". Por isso, pode-se perceber uma inflexão histórica indicando um projeto de desmobilizar ou desorganizar essa teia política local. É importante observar que, no início do século XIX, a conquista portuguesa ainda não apresentava como objetivo primordial difundir o português, mas, antes, continuava a resignar-se aos idiomas locais mais amplamente compartilhados. Além dos missionários, as autoridades públicas deveriam também passar a entender a língua de Angola: "[...] convém que aqueles, aos quais está incumbido o governo, e a administração da Justiça em qualquer país, saibam o idioma, que nele se fala. Se tais pessoas não tiverem esta inteligência, constituem-se na indispensável necessidade dos intérpretes", o que pode ser perigoso, pois segredos e disposições políticas e militares seriam do conhecimento de um "preto venal": "E será justo que 
homens de tão pouca instrução, e confiança, sejam instrumentos necessários do bem, e conservação pública?" (CANNECATTIM 1804, p. iii-iv). Como, então, estariam a religião, justiça, administração e comércio sob "a opaca sombra de um Negro intérprete?" (CANNECATTIM 1804, p. v).

A dedicação ao estudo da língua justificava-se também na extensão da área em que estaria representada:

Nem é de pequena extensão o terreno, em que esta Língua se fala, como farei brevemente ver, servindo à curiosidade do Leitor, e, recomendando ao mesmo tempo ainda mais a importância da obra. Fala-se a Língua Bunda em todo o País, que se chama Reino de Angola, ou Reino dos Abundos, que compreende um território de maior extensão que Portugal.

Ainda que o Reino de Angola pela costa não se estende a mais de quarenta a cinquenta léguas, contudo dilata-se muito para dentro do Sertão; e tanto que, em Cassanc'i, que é a Feira mais entranhada nele, falam aqueles Povos a Língua Bunda, como fui certificado por vários Pombeiros, que haviam estado naquelas partes fazendo negócio de escravatura, cera, e marfim. [...] de sorte que em todos os Distritos, Feiras, Presídios, e Freguesias dos três Rios Cuanza, Senza e Dande, e ainda os Povos do Rio Luffuni (excetuando os moradores da Bança do Libungo, que falam em Língua do Congo) todos se explicam em Bundo até o Presídio das Pedras de Encogi, onde uns falam a Língua Bunda, e outros a do Congo (CANNECATTIM 1804, p. vi-vii).

Além da mudança na política colonial que a obra de Cannecattim parece representar, relativa à eficácia da presença portuguesa na região, o missionário traça um quadro da extensão territorial em que a língua é falada, utilizando o conceito de língua geral (CANNECATTIM 1804, p. ix), justificado pela "extensão vastíssima de países" onde seria corrente e pela possibilidade de intercompreensão com grupos falantes de outras línguas que menciona. A obra desse missionário é um contraponto importante neste artigo, pois, ao abordar diretamente o domínio linguístico, o tratamento da questão da diversidade é bem diferente. Tal diversidade, longe de ser recusada ou estereotipada no campo do incomunicável, é decifrada, encontrando-se os canais de comunicação, como mostra o registro da existência de uma língua geral.

No conjunto de relatos e perspectivas aqui analisadas, relativas a regiões distintas, o quadro que se desenha é o de uma intensa comunicação, de técnicas de entendimento da língua do outro, tanto entre os povos africanos como entre os europeus. Parece assim pouco provável acreditar na eficácia da separação de africanos como um obstáculo para a comunicação. No que diz respeito a uma suposta intenção deliberada dos agentes do tráfico envolvidos com a travessia em embarcar falantes de línguas diferentes para evitar revoltas nos navios, tratase também de algo pouco eficaz diante de constrangimentos de outras ordens que envolviam o acesso aos cativos. A crítica historiográfica ao tópos diversidade/ incomunicabilidade mostrou o quanto determinadas representações podem ganhar um status de verdade e uma espécie de vida própria. Ainda que não nos caiba explicar o porquê, cabe-nos prestar atenção aos efeitos de tais imagens e desconstruí-las com a pesquisa mais cuidadosa, não só baseada em documentação, mas também em leituras teóricas e no exame cuidadoso dos contextos históricos. 


\section{Referências bibliográficas}

ABREU, Marcos. Ladinos e boçais: o regime de línguas do contrabando de africanos (1831-c.1850). Dissertação (Mestrado em História) - Programa de Pós-Graduação em História, Universidade Estadual de Campinas, Campinas, 2012.

As vozes centro-africanas no Atlântico Sul (1831-1850). In: LIMA, Ivana Stolze; CARMO, Laura (Org.). História social da língua nacional: diáspora africana. Rio de Janeiro: Nau, 2014, p. 73-103. v. 2.

ALENCASTRO, Luiz Felipe de. 0 trato dos viventes: formação do Brasil no Atlântico Sul. São Paulo: Companhia das Letras, 2000.

ASENSIO, Eugenio. La lengua compañera del imperio. Historia de una idea de Nebrija en España y Portugal. Revista de Filologia Española, t. xliii, n. 43, p. 339-413, 1960.

AUROUX, Sylvain. A revolução tecnológica da gramatização. Campinas: Unicamp, 2009.

AZEVEDO, Elisa Dias Ferreira de. Língua ambunda em foco: nos rastros de Bernardo Maria Cannecattim. Programa de Incentivo à Produção do Conhecimento da Fundação Casa de Rui Barbosa. Rio de Janeiro: Casa de Rui Barbosa, 2015. Relatório final.

BONVINI, Emilio; BUSUTTIL, Joëlle; PEYRAUBE, Alain (Org.). Dictionnaire des langues. Paris: PUF, 2011.

CADORNEGA, Antônio de Oliveira de. História geral das guerras angolanas 1680-1681. Lisboa: Agência Geral do Ultramar, v. 3, 1972.

CALLOU, Dinah. Sobre a história do português no e do Brasil: levantando questões. In: AVELAR, Juanito Ornelas; LÓPEZ, Laura Álvarez (Org.). Língua(s) e História(s). Frankfurt: Peter Lang Edition, 2015.

CANNECATTIM, Bernardo Maria de. Diccionario da lingua bunda ou angolense, explicada na portuguesa e latina. Lisboa: Impressão Régia, 1804.

Colleção de observações grammaticaes sobre a lingua bunda ou angolense. Lisboa: Impressão Régia, 1805.

CANOT, Theodore. Captain Canot, or Twenty Years of an African Slaver. New York: Appleton, 1854.

CANUT, Cécile. À la frontière des langues. Figures de la démarcation. Cahiers d'Etudes Africaines, v. 41, n. 163-164, p. 443-464, 2001.

CARTA DE LEI de Dom Pedro II proibindo que os negros cativos levados para de Angola para as partes do Brasil fossem transportados e tratados com desumanidade, 18 março de 1684. Angola: Arquivo Histórico Ultramarino, cx. 12 doc. 137. 
CARTA A EL REI sobre os capelães.Angola: Arquivo Histórico Ultramarino, 1686. In: BRÁSIO, António. Monumenta Missionária Africana. Lisboa, Agência Geral do Ultramar, 1956, v. XIV, 1985, p. 34-36. CD-ROM: Lisboa: Instituto de Investigação Científica Tropical, 2013.

CARVALHO, Flávia. Ngolas, sobas, tandalas e macotas: hierarquia e distribuição de poder no antigo reino do Ndongo. In: RIBEIRO, Alexandre; GEBARA, Alexsander; BITTENCOURT, Marcelo (Org.). África passado e presente: II Encontro de estudos africanos da UFF. Niterói: Ed. UFF, 2010, p. 35-53.

CONSULTA do Conselho Ultramarino, 20/11/1694. Angola: Arquivo Histórico Ultramarino. In: BRÁSIO, António. Monumenta Missionária Africana. Lisboa: Agência Geral do Ultramar, 1956, v. VII, p. 380-381. CD-ROM: Lisboa: Instituto de Investigação Científica Tropical, 2013.

CURTO, Diogo Ramada. O sistema do escravo-intérprete, cultura imperial e projetos coloniais (século XV a XVIII). Campinas: Ed. Unicamp, 2009.

FAYER, Joan M. African Interpreters in the Atlantic Slave Trade. Anthropological Linguistics, v. 45, n. 3, p. 281-295, 2003.

FERREIRA, Roquinaldo. Cross-Cultural Exchange in the Atlantic World. Cambridge: Cambridge University Press, 2012.

GUISAN, Pierre. Língua: a ambiguidade do conceito. In: BARRETO, Monica; SALGADO, Ana (Org.). Sociolinguística no Brasil: uma contribuição dos estudos sobre línguas em/de contato. Rio de Janeiro: Edição 7 Letras, 2009, p. 17-27.

HAMPATÉ BÂ, Amadou. Amkoullel, o menino fula. São Paulo: Palas Athena; Casa das Áfricas, 2003.

HEINTZE, Beatrix. A lusofonia no interior da África Central na era pré-colonial. Um contributo para a sua história e compreensão na actualidade. Cadernos de Estudos Africanos, n. 7-8, p. 179-207, 2005.

HOUAISS, Antonio. O Português no Brasil. Pequena enciclopédia de cultura brasileira. Rio de Janeiro: Unibrade, 1985.

KLUGE, Angela. The Gbe language continuum of West Africa: a synchronic typological approach to prioritizing in-depth sociolinguistic research on literature extensibility. Language documentation \& Conservation, v. 1, n. 2, p. 182-215, 2007.

LARA, Silvia. Legislação sobre escravos africanos na América Portuguesa. In: ANDRÉS-GALLEGO, José (Coord.). Nuevas Aportaciones a la Historia Jurídica de Iberoamérica. Madrid: Fundación Histórica Tavera; Digibis; Fundación Hernando de Larramendi, 2000.

. Linguagem, domínio senhorial e identidade étnica nas Minas Gerais de meados do século XVIII. In: ALMEIDA, Miguel Valle de et al. (Org.). Trânsitos Coloniais. Lisboa: Imprensa de Ciências Sociais, 2002, p. 205-225. 
LEWIS, M. Paul; SIMONS, Gary F.; FENNIG, Charles D. (Ed.). Ethnologue: Languages of the World. Dallas: SIL International, [s.n.]. Avaible on: $<$ www.ethnologue.com>.

LIMA, Ivana Stolze. Escravos bem falantes e nacionalização linguística no Brasil - uma perspectiva histórica. Estudos Históricos, v. 25, n. 50, p. 352-369, 2012.

Diz que é forro - práticas de comunicação escrava em anúncios de jornal. In: AVELAR, Juanito Ornelas de; LÓPEZ, Laura Álvarez (Org.). Dinâmicas Afro-Latinas. Língua(s) e História(s). Frankfut: Peter Lang Edition, 2015, p. 31-41.

. Escravidão e comunicação no mundo atlântico, em torno da "língua de Angola", século XVII. História Unisinos, v. 21, n. 1, p. 109-121, 2017.

MARZANO, Andrea. Cantigas desaforadas e outras injúrias: o português e o quimbundo em Luanda (1870-1930). In: LIMA, Ivana Stolze; CARMO, Laura (Org.). História social da língua nacional: diáspora africana. Rio de Janeiro: Faperj/Nau, 2014, p. 105-119. v. 2.

NATIONAL MUSEUM of AFRICAN ART, Washington. Linguist staff. Disponível em: <http://africa.si.edu/collections/view/objects/asitem/search\$0040/ 0?t: state:flow=72ac3541-f0f9-44da-a571-217929c6436c>. Acesso em: jun. 2016.

PEIXOTO, Antonio da Costa. Obra nova da língua geral de mina. Lisboa: Agência Geral das Colônias, 1945 [manuscrito de 1741].

PETTER, Margarida. Línguas do grupo banto. In: LIMA, Ivana Stolze; CARMO, Laura (Org.). História social da língua nacional: diáspora africana. Rio de Janeiro: Nau, 2014, p. 349-352. v. 2.

PINHEIRO, Claudio. Língua e conquista: formação de intérpretes e políticas imperiais portuguesas de comunicação em Ásia nos alvores da modernidade. In: LIMA, Ivana Stolze; CARMO, Laura (Org.). História Social da Língua Nacional. Rio de Janeiro: Edições Casa de Rui Barbosa, 2008, p. 29-64.

RODRIGUES, Jaime. De costa a costa. Escravos, marinheiros e intermediários do tráfico negreiro de Angola ao Rio de Janeiro (1780-1860). São Paulo: Companhia das Letras, 2005.

RODRIGUES, José Honório. A vitória da língua portuguesa no Brasil colonial. Humanidades, v. I, n. 4, 1983.

SANTOS, Catarina Madeira. Escrever o poder. Os autos de vassalagem e a vulgarização da escrita entre as elites africanas ndembu. Revista de História, n. 155, p. 81-95, 2006.

SILVA, Alberto da Costa e. As relações entre o Brasil e a África Negra, de 1822 à Primeira Guerra Mundial. In: Um Rio chamado Atlântico. A África no Brasil e o Brasil na África. Rio de Janeiro: Nova Fronteira, 2003, p. 11-52. 
SILVA, Eduardo. Escravidão e linguagem. Rio de Janeiro: Faculdade de Letras da UFRJ, 2000.

SLENES, Robert. Malungu, ngoma vem! África coberta e descoberta no Brasil. Revista USP, n. 12, p. 48-67, 1992.

SteVenson, A; LindBeRG, C. (Ed.). New Oxford American Dictionary. 3. ed. New York: Oxford University Press, 2010.

SMITH, William. New Voyage to Guinea. London: John Nourse, 1745. Disponível em: <http://brasilafrica.fflch.usp.br/node/197>. Acesso em jan. 2017.

SOUSA, Frei Luís de. Annaes de Elrei Dom João Terceiro. Lisboa: Sociedade Propagadora dos Conhecimentos Úteis, 1844.

THORNTON, John. A África e os africanos na formação do mundo atlântico. Rio de Janeiro: Elsevier, 2004.

VANSINA, Jan. Portuguese vs kimbundu: language use in the colony of Angola (1575-c.1845). Bulletin des Séances Académie Royale des Sciences d'Outre-Mer, v. 47, n. 3, p. 267-281, 2001.

VARNHAGEN, Francisco Adolfo de. História Geral do Brasil: antes de sua separação e independência de Portugal. São Paulo: Melhoramentos, 1975 [1854-1857].

WEBSTER, N. Webster's Practical Dictionary. New York: Grossete \& Dunlap, 64 1932. 